\title{
INVESTIGATION OF HOT IN-PLACE RECYCLING EFFECTS ON HOT MIX ASPHALT PAVEMENT
}

\author{
Dr Nadeem Anwer Qureshi, Assistant Professor, Military College of Engineering (MCE), National \\ University of Science and Technology (NUST), Risalpur Campus, Pakistan. Email: \\ nza0014@tigermail.auburn.edu
}

Dr Bilal Khurshid, Associate Professor, Military College of Engineering (MCE), National University of Science and Technology (NUST), Risalpur Campus, Pakistan. Email: mbilal@mce.nust.edu.pk

doi: 10.1515/ijpeat-2015-0006

\begin{abstract}
In March 2006, a hot in-place recycling (HIR) technique was employed for the first time on Lahore-Islamabad Motorway (M-2) to rehabilitate sections where the rut depth was about $40 \mathrm{~mm}$. Since HIR technology was new to Pakistan, research was carried out to study the effects of recycled wearing course on overall pavement performance. This was accomplished by comparing structural adequacy of pavement and material characterization before and after recycling. Laboratory investigations included hot mix asphalt (HMA) volumeteric analysis, aggregate gradation analysis, extracted asphalt properties (penetration test and dynamic shear rheometer (DSR)) and resilient modulus. Analysis of recycled HMA wearing course indicated a reduction in modulus for a mix which was stiff and aged prior to recycling. Relative degradation of the aggregates in HMA wearing course, before and after recycling, was observed; however, it remained close to National Highway Authority (NHA) standard specifications. The research enhanced awareness of HIR among local engineers and contractors.
\end{abstract}

Keywords: (Hot in-place recycling, Resilient modulus, Volumetrics, Gradation, Dynamic shear rheometer, Performance grade)

\section{BACKGROUND}

Enormous increase in vehicular traffic, increased use of hot mix asphalt (HMA) pavements, ensuring traffic flow during execution of work, maintenance of geometrics and removal of old pavements are challenging pavement management tasks for any agency. Efficient rehabilitation techniques with minimal waste of valuable construction materials have become a necessity of the time in management of pavements at acceptable serviceability levels (AASHTO, 1993). Among the recycling techniques, hot in-place recycling (HIR) has proven to be a viable on-site method for rehabilitation of pavements at low costs with minimal use of new materials. HIR can successfully treat surface defects such as corrugation, surface rutting and longitudinal and slippage cracking to a depth of $50 \mathrm{~mm}$ (Kandhal and Mallick, 1997). In Pakistan, HIR technique was first used in March 2006 on the Lahore - Kala Shah Kaku section of Lahore-Islamabad Motorway (M-2) which had been in service since November 1997. The surface recycling technique of HIR was mostly performed on the sections rutted to a depth of 38-50 $\mathrm{mm}$. 


\section{SCOPE AND OBJECTIVE}

The objective of this study was to conduct comparative evaluation of the selected pavement sections before and after HIR. Research involved both field work and laboratory investigations. Field work involved HMA coring before and after recycling and recording temperatures during various stages of HIR. Laboratory investigations included HMA volumetric analysis, aggregate gradation analysis, extracted asphalt properties (penetration test and DSR) and resilient modulus before and after recycling the selected pavement sections.

\section{MATERIALS AND METHODS}

\section{Methodology}

The methodology adopted for this research before and after recycling is illustrated in Figure 1.

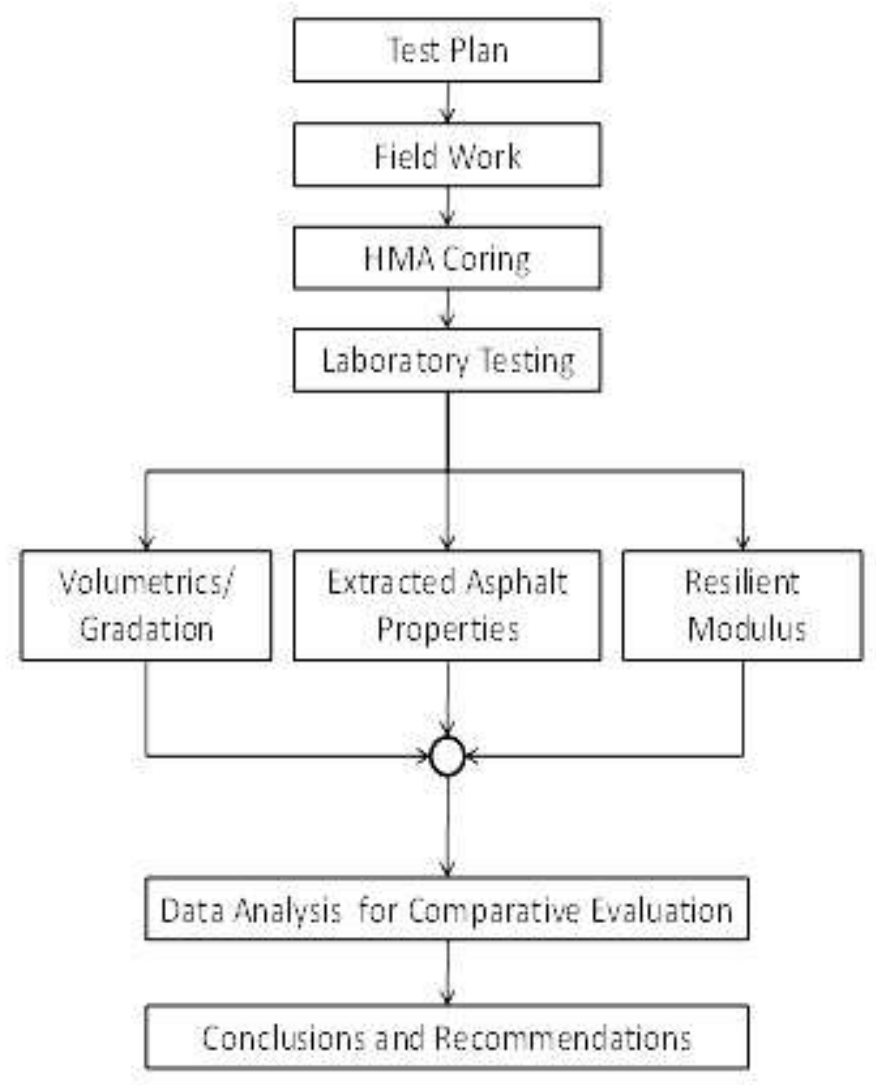

Figure 1. Evaluation methodology for the research

\section{Site selection}

The test site was selected on the south-bound carriageway of M-2, approximately 20 $\mathrm{km}$ from Islamabad near Chakri. It was divided into three sections of $150 \mathrm{~m}$ each separated by a $10 \mathrm{~m}$ transition length as shown in Figure 2. The original pavement design of the test sections is illustrated in Figure 3. The coring plan is illustrated in Figure 4. All cores were $102 \mathrm{~mm}$ diameter with thickness ranging between $44 \mathrm{~mm}$ (1.73”) and $55 \mathrm{~mm}\left(2.17^{\prime \prime}\right)$. 

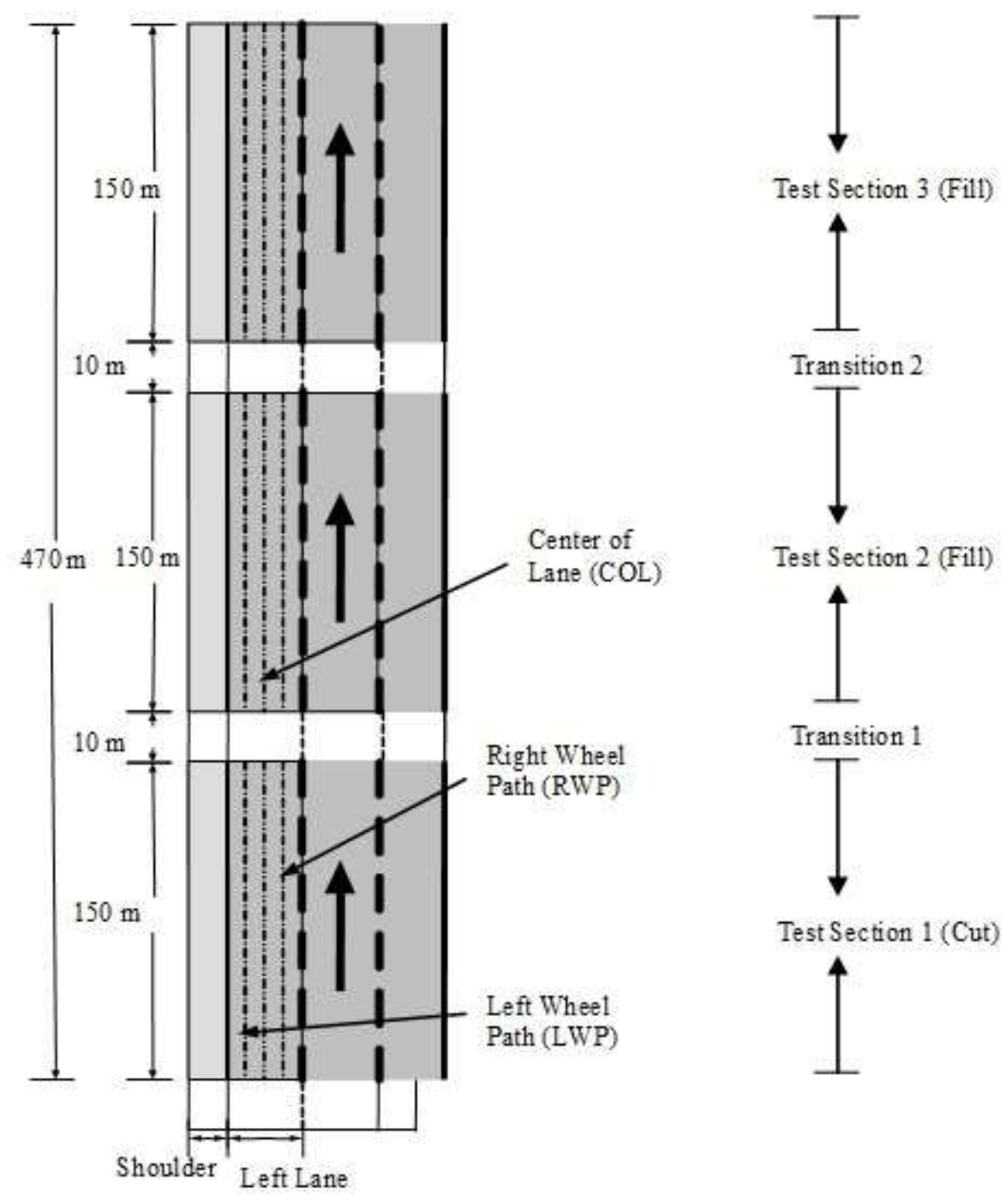

Transition 2

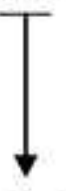

Test Section 2 (Fill)

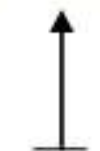

Transition 1

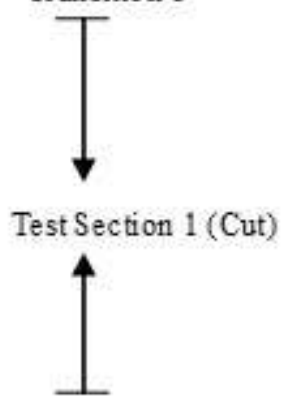

Figure 2. Division of test site into sections

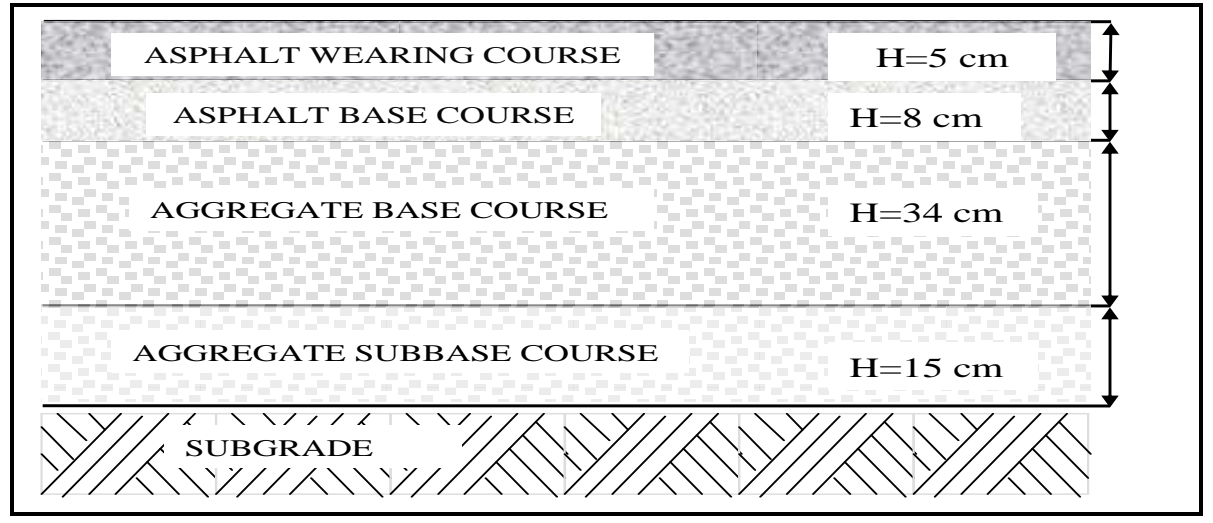

Figure 3. Cross section details of test sections 

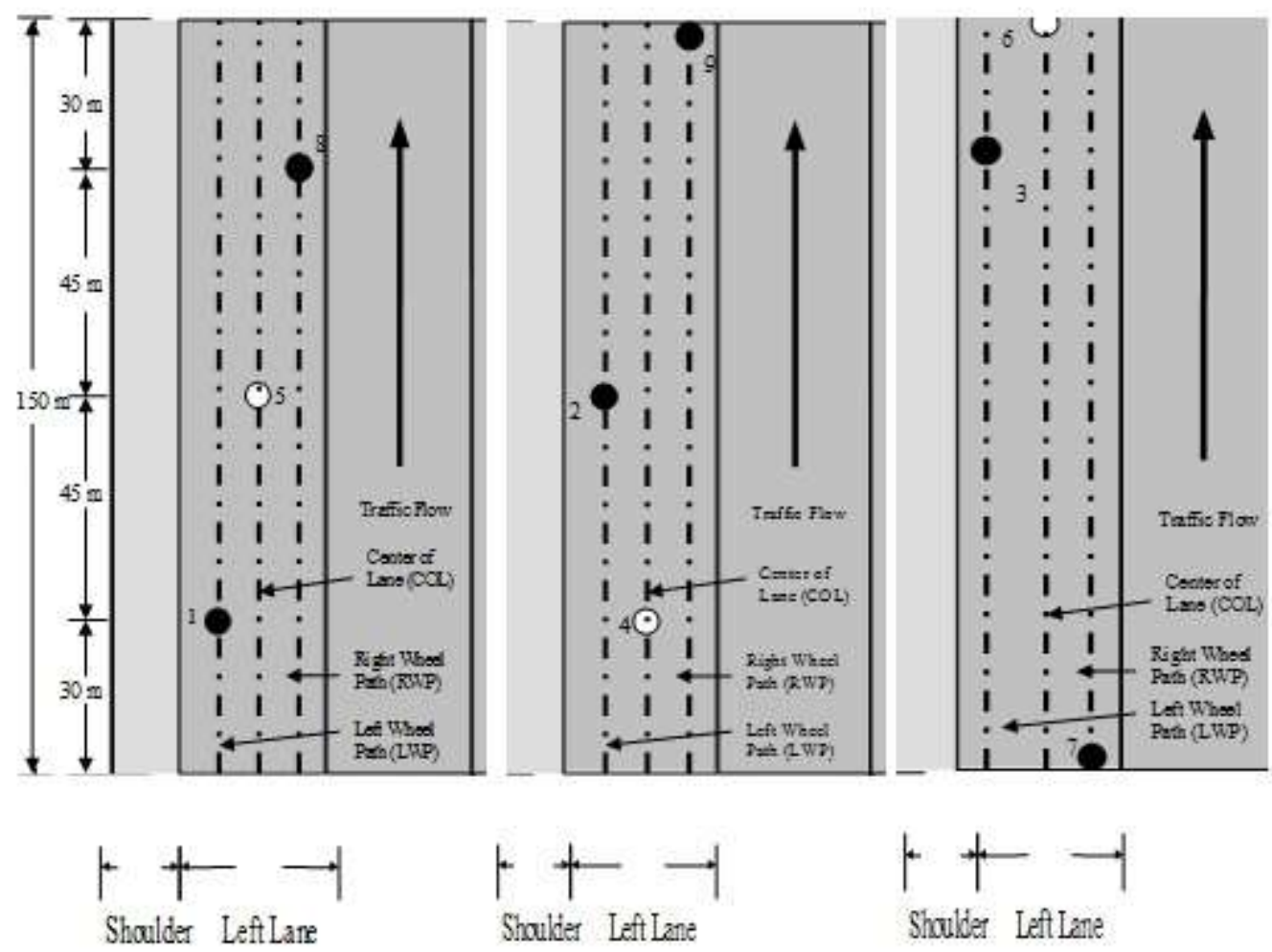

Shoulder Left Lane

\section{Shaulies Left Lane}

\section{Shoulder Left Lane}

Core Location Before and
After Recycling
Core Location Before Recycling

(a) Section 1

(b) Section 2

(c) Section 3

Figure 4. Coring plan within a test section

\section{HIR equipment}

The recycling unit used on this project is a German made, hot recycling unit by Wirtgen. The unit consists of two main parts, i.e. Panel heating machine HM 4500 and Remixer RX 4500. The units are shown in Figure 5, 6 and 7.

Technical specifications of the panel heating machine HM 4500 and Remixer RX 4500 units are tabulated in Table 1 and 2. HM 4500 heats pavement gently by infrared heater elements up to $60 \mathrm{~mm}$ of depth.

Table 1. Salient features of panel heating machine HM 4500

\begin{tabular}{|c|c|}
\hline Heating Width (max) & $4.50 \mathrm{~m}$ \\
\hline Heating Area & $44.64 \mathrm{~m}^{2}$ \\
\hline Heater Elements (adjustable) & Infrared \\
\hline Max. Heating Performance & $2,260 \mathrm{~kW}$ \\
\hline Volume Gas Tank (Propane) & 6,000 liters \\
\hline Engine Output & $79 \mathrm{~kW}$ \\
\hline Operating Weight & $22,600 \mathrm{~kg}$ \\
\hline
\end{tabular}


The International Journal of Pavement Engineering and Asphalt Technology (PEAT) ISSN 1464-8164.

Volume: 16, Issue: 2, December 2015, pp.7-20

Table 2. Salient features of Remixer RX 4500

\begin{tabular}{|c|c|}
\hline Working Width & $3.0-4.5 \mathrm{~m}$ \\
\hline Working Depth & $0-60 \mathrm{~mm}$ \\
\hline Engine Output & $220 \mathrm{~kW}$ \\
\hline Operating Weight & $48,820 \mathrm{~kg}$ \\
\hline Number of Wheels & 4 \\
\hline Max. Heating Performance & $2,210 \mathrm{~kW}$ \\
\hline Travel Drive System & Hydraulic / all-wheel \\
\hline
\end{tabular}

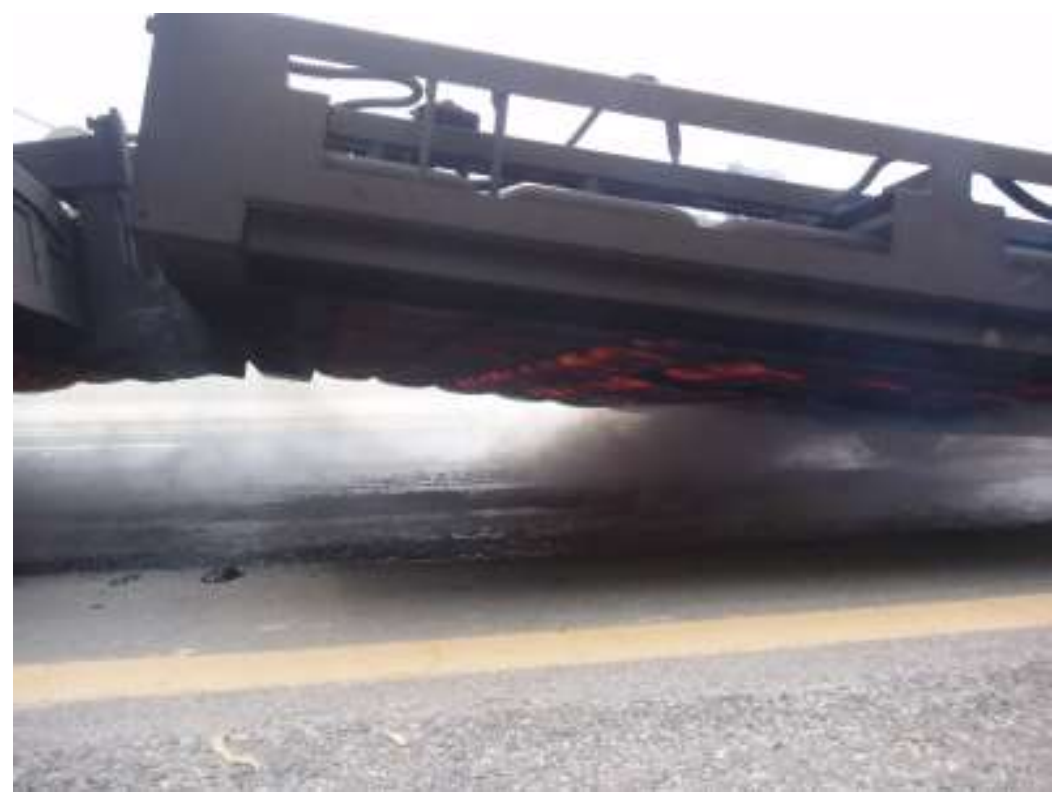

Figure 5. Pre-heating unit

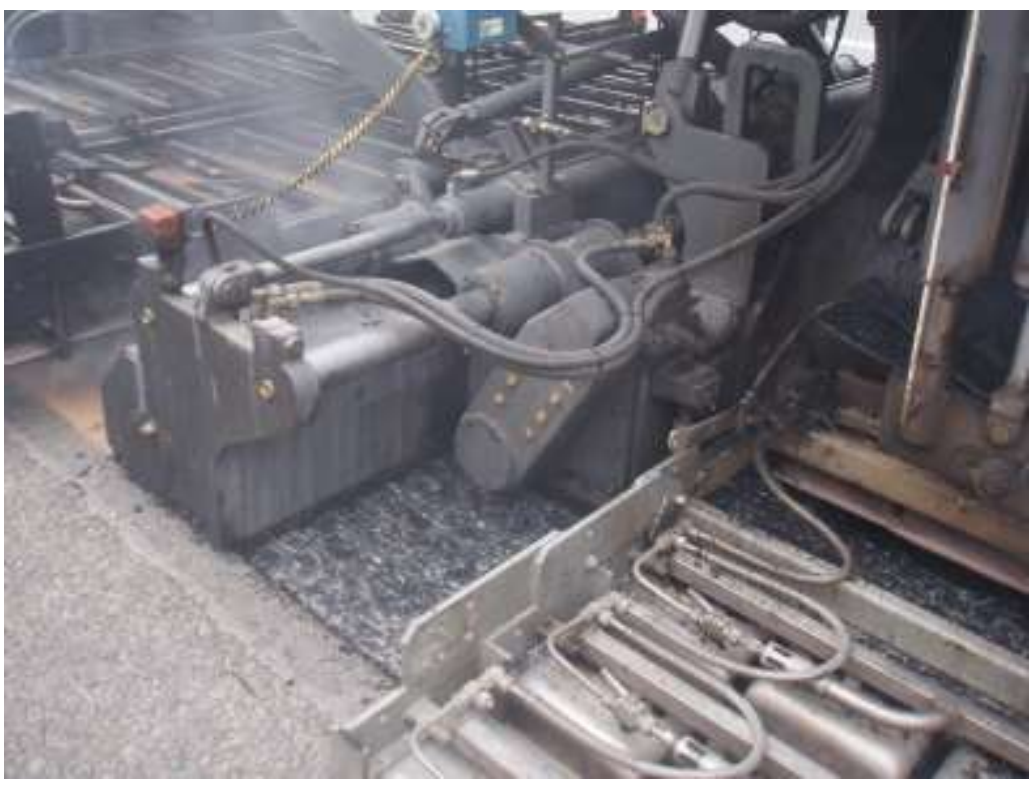

Figure 6. Scarifying and heating unit 


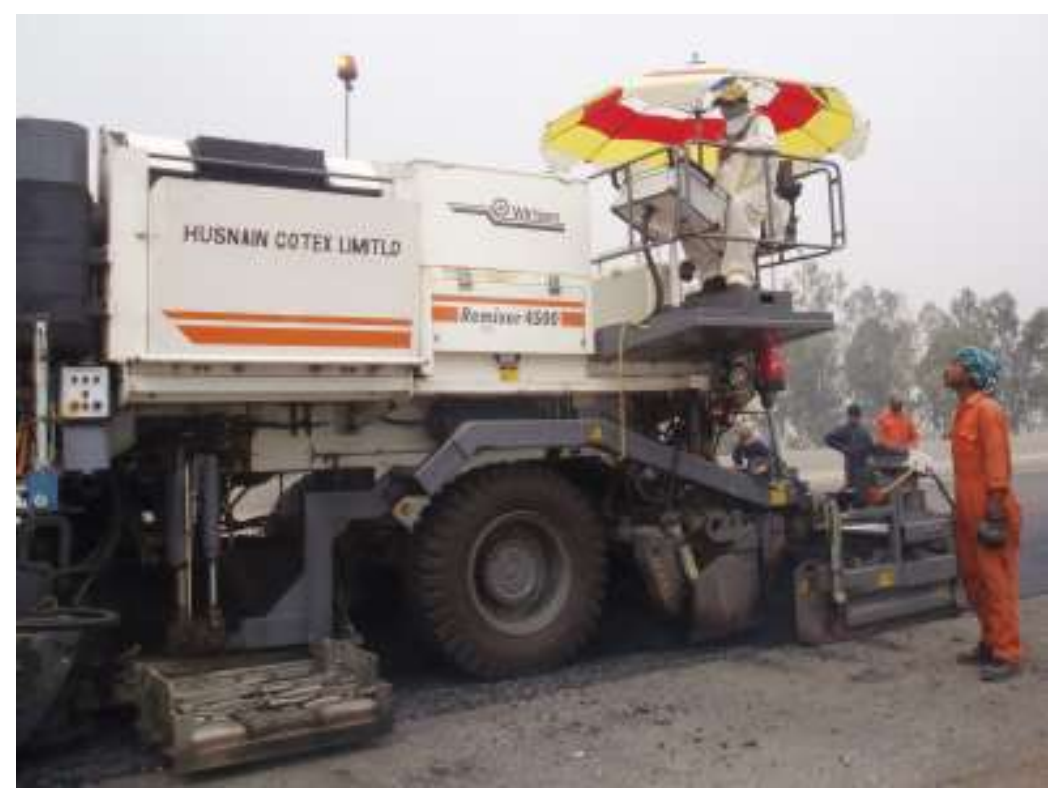

Figure 7. Remixing unit

\section{Field testing}

The coring plan is illustrated in Figure 4. A total of 9 HMA wearing course cores (3 cores from each section) before recycling and 6 HMA wearing course cores (2 cores from each section) after recycling were extracted for further laboratory testing and evaluation.

During the application of the HIR process on March 5, 2007, temperatures were measured at various stages of recycling. Surface temperatures recorded at different times during various stages of the HIR process are tabulated in Table 3. There were three panels in front and one on rear of panel heating machine HM 4500. According to Table 6-4 of Roberts et al. (2009), minimum laydown temperature for $5 \mathrm{~cm}$ (2") with base temperature greater than $32^{\circ} \mathrm{C}\left(90^{\circ} \mathrm{F}\right)$, should be around $126^{\circ} \mathrm{C}\left(260^{\circ} \mathrm{F}\right)$. Temperatures recorded at different times during various stages of the HIR process indicated that they were well below the guidelines provided by Roberts et al. (1996), even though in HIR laydown temperatures are lower than conventional HMA. About $1 \%$ fresh asphalt binder (penetration grade 60-70) was added during the recycling process. Virgin aggregate and new HMA was not added during HIR on test sections.

\section{Laboratory testing}

\section{Resilient modulus testing}

The cores removed from test sections before and after recycling as illustrated in Figure 4 were brought back to the laboratory for further testing. The wearing course was separated from HMA cores. Resilient modulus testing was performed on HMA wearing course cores (102 mm diameter) according to ASTM D 4123 and the laboratory testing procedure by Barksdale et al. (1997). A universal testing machine (UTM-5P) by Industrial Process Control Global-IPC (IPC) was used for the tests. A total of 9 asphalt concrete wearing course cores ( 3 cores from each section) before and 6 asphalt concrete wearing course cores (2 cores from each section) after recycling with thickness ranging between $44 \mathrm{~mm}$ (1.73”) and $55 \mathrm{~mm}$ (2.17”) were 
tested. Barksdale et al. (1997), suggest load ranges of 30,15 , and $4 \%$ of tensile strength measured at $25^{\circ} \mathrm{C}$ to be used in conducting the test at temperatures of $5 \pm 1$, $25 \pm 1$, and $40 \pm 1^{\circ} \mathrm{C}$, respectively. The indirect tensile strength of asphalt cores was determined by using a Marshall loading frame based on TXDOT Designation: Tex226- $F$. A Haversine load duration of $0.1 \mathrm{sec}$ with rest period of $0.9 \mathrm{sec}$ (frequency, $1 \mathrm{~Hz}$ ) was used for resilient modulus testing as recommended by Barksdale et al. (1998). Poisson's ratio values used during the resilient modulus testing were as recommended by Von Quintus et al. (2002). Temperature, loads, preconditioning cycles and Poisson's ratio used for resilient modulus testing of HMA wearing course cores before and after recycling are tabulated in Table 4. The summary of resilient modulus test results of HMA wearing course cores before and after recycling is tabulated in Table 5. Core designation includes whether the core is taken before or after recycling (BR/Before Recycling, AR/After Recycling), location (L/Left Wheel Path, C/Center of the Lane, and R/Right Wheel Path), test section number, and core number.

Table 3. Temperatures $\left({ }^{\circ} \mathrm{C}\right)$ during various stages of HIR process

\begin{tabular}{|c|c|c|c|c|c|c|c|c|}
\hline \multirow{2}{*}{$\begin{array}{l} \\
\\
0 \\
0 \\
0 \\
0 \\
0 \\
0 \\
z \\
0\end{array}$} & \multirow{2}{*}{ 实 } & \multirow{2}{*}{$\underset{\stackrel{\varpi}{\sigma}}{\forall}$} & \multicolumn{3}{|c|}{ 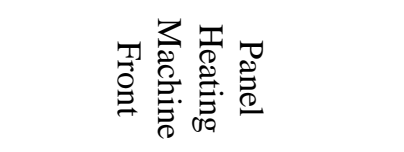 } & \multirow{2}{*}{ 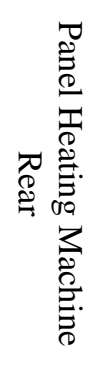 } & \multirow{2}{*}{ 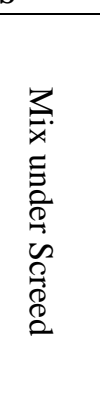 } & \multirow{2}{*}{ 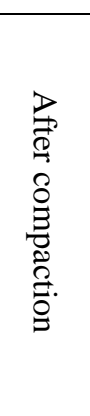 } \\
\hline & & & 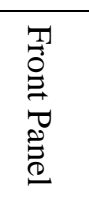 & 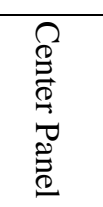 & 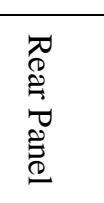 & & & \\
\hline 1 & 1000 & $\begin{array}{c}5^{\text {th }} \\
\text { March } \\
2007\end{array}$ & 81.8 & 92.5 & 127.0 & 136.0 & 92.0 & 66.0 \\
\hline 1 & 1200 & $\begin{array}{c}5^{\text {th }} \\
\text { March } \\
2007\end{array}$ & 90.0 & 102.0 & 150.0 & 155.0 & 97.0 & 70.0 \\
\hline 2 & 1300 & $\begin{array}{c}5^{\text {th }} \\
\text { March } \\
2007\end{array}$ & 100 & 117.0 & 170.0 & 175.0 & 102.0 & 74.0 \\
\hline 2 & 1400 & $\begin{array}{c}5^{\text {th }} \\
\text { March } \\
2007\end{array}$ & 85.0 & 96.0 & 135.0 & 145.0 & 95.0 & 69.0 \\
\hline 3 & 1600 & $\begin{array}{c}5^{\text {th }} \\
\text { March } \\
2007\end{array}$ & 94.0 & 107.0 & 160.0 & 160.0 & 101.0 & 72.0 \\
\hline Average & & & 90 & 103 & 148 & 154 & 97 & 70 \\
\hline
\end{tabular}

Table 4. Test procedure parameters for resilient modulus testing

\begin{tabular}{|c|c|c|c|c|}
\hline Temperature $\left({ }^{\circ} \mathrm{C}\right)$ & $\begin{array}{c}\text { Load }(\mathrm{N}) \\
\text { before } \\
\text { Recycling }\end{array}$ & $\begin{array}{c}\text { Load }(\mathrm{N}) \\
\text { after } \\
\text { Recycling }\end{array}$ & Cycles (No.) & Poisson's ratio \\
\hline 5 & 1250 & 1100 & 100 & 0.25 \\
\hline 25 & 625 & 550 & 100 & 0.30 \\
\hline 40 & 150 & 150 & 50 & 0.40 \\
\hline
\end{tabular}


Table 5. HMA wearing course resilient modulus test results

\begin{tabular}{|c|c|c|c|c|}
\hline \multirow{2}{*}{ Sample No. } & \multicolumn{3}{|c|}{ Modulus (MPa) } & \multirow[t]{2}{*}{ Bulk Specific Gravity } \\
\hline & $5^{0} \mathrm{C}$ & $25^{0} \mathrm{C}$ & $40^{\circ} \mathrm{C}$ & \\
\hline \multicolumn{5}{|c|}{ Before recycling } \\
\hline BRL-1-1 & 15662 & 10724 & 3975 & 2.44 \\
\hline BRC-1-5 & 16479 & 7390 & 3397 & 2.44 \\
\hline BRR-1-8 & 18558 & 10553 & 3040 & 2.46 \\
\hline Average & 16900 & 9556 & 3471 & 2.45 \\
\hline BRL-2-2 & 21246 & 8348 & 2436 & 2.46 \\
\hline BRC-2-4 & 25801 & 11535 & 2891 & 2.46 \\
\hline BRR-2-9 & 16429 & 7806 & 2328 & 2.46 \\
\hline Average & 21159 & 9230 & 2552 & 2.46 \\
\hline BRL-3-3 & 16172 & 6585 & 1427 & 2.46 \\
\hline BRC-3-6 & 16673 & 10880 & 2219 & 2.44 \\
\hline BRR-3-7 & 12813 & 4447 & 1040 & 2.32 \\
\hline Average & 15219 & 7304 & 1562 & 2.41 \\
\hline Overall Average & 17759 & 8696 & 2528 & 2.44 \\
\hline Std Dev & 3766 & 2385 & 923 & 0.05 \\
\hline $\mathrm{CoV}$ & $21 \%$ & $27 \%$ & $36 \%$ & $2 \%$ \\
\hline \multicolumn{5}{|c|}{ After recycling } \\
\hline ARL1-1 & 11536 & 3253 & 802 & 2.28 \\
\hline ARR1-8 & 9054 & 3437 & 940 & 2.34 \\
\hline Average & 10295 & 3345 & 871 & 2.31 \\
\hline ARL2-2 & 10547 & 4718 & 953 & 2.33 \\
\hline ARR2-9 & 8447 & 2318 & 672 & 2.28 \\
\hline Average & 9497 & 3518 & 813 & 2.30 \\
\hline ARL3-3 & 9405 & 2059 & 550 & 2.26 \\
\hline ARR3-7 & 9586 & 2646 & 625 & 2.27 \\
\hline Average & 9496 & 2352 & 588 & 2.27 \\
\hline Overall Average & 9763 & 3072 & 757 & 2.29 \\
\hline Std Dev & 1109 & 965 & 168 & 0.03 \\
\hline $\mathrm{CoV}$ & $11 \%$ & $31 \%$ & $22 \%$ & $1.50 \%$ \\
\hline
\end{tabular}

\section{Volumetrics and gradation testing}

Bulk specific gravity of asphalt concrete core specimens was tested in accordance with AASHTO T 166-07. Extraction procedures for removing asphalt from aggregates in an asphalt mixture followed the methods listed in ASTM D2172 (Centrifuge Extraction). Recovery of asphalt binder from solution was done with binder recovery apparatus 45-3720 by ELE international according to British Standard, BS 598. Volumetric properties of asphalt wearing course cores before, and after recycling are tabulated in Table 6. The gradation envelopes of HMA wearing course before and after recycling are illustrated in Figure 8 and 9. 


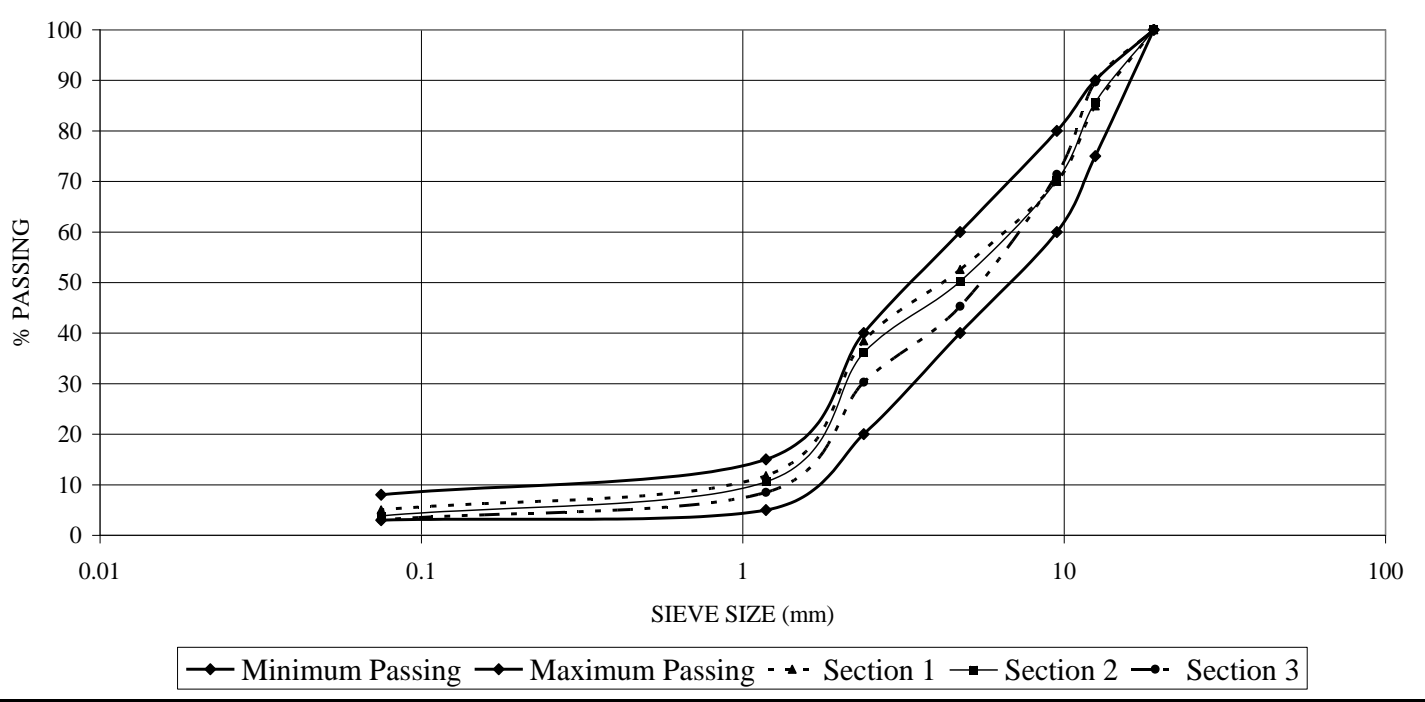

Figure 8. Gradation analysis of HMA wearing course cores before recycling

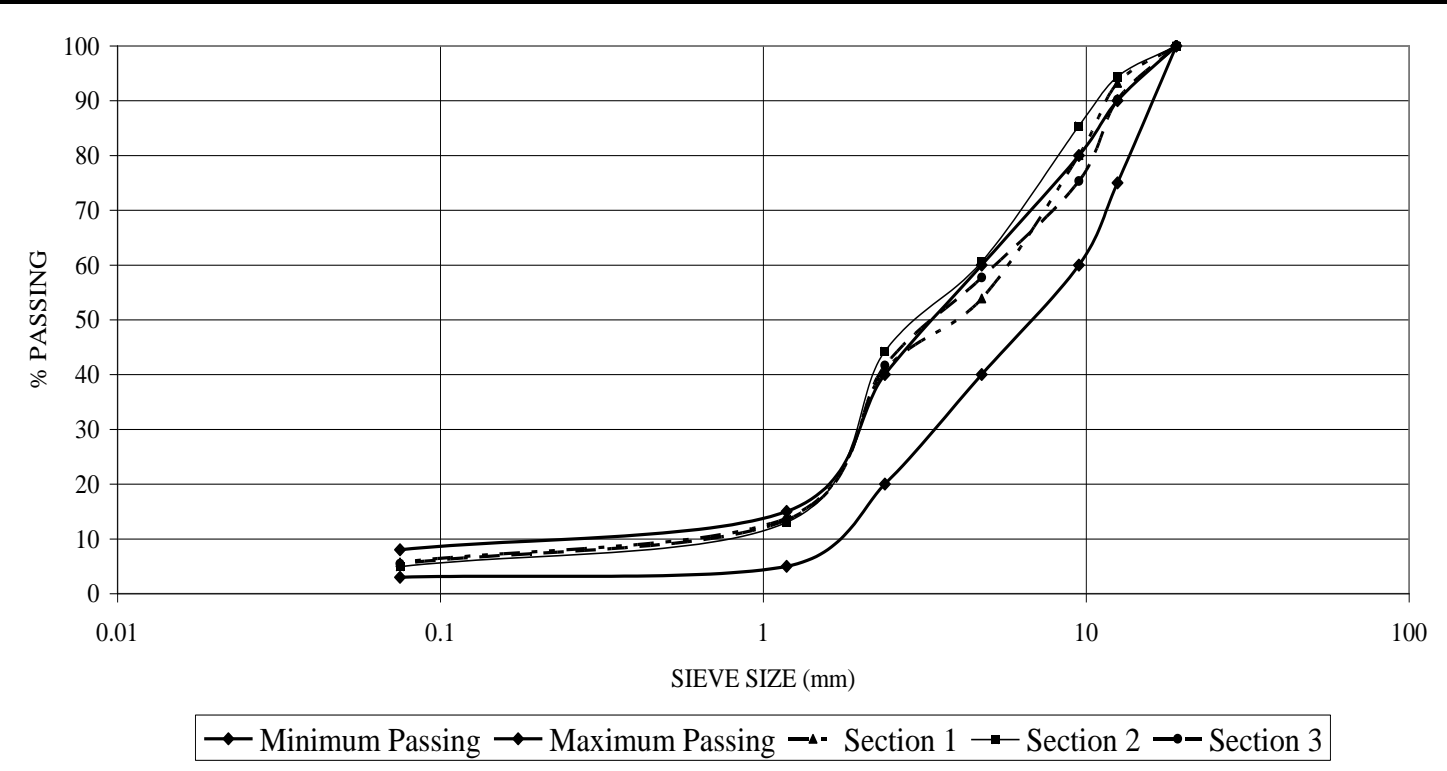

Figure 9. Gradation analysis of HMA wearing course cores after recycling 
The International Journal of Pavement Engineering and Asphalt Technology (PEAT) ISSN 1464-8164.

Volume: 16, Issue: 2, December 2015, pp.7-20

\begin{tabular}{|c|c|c|c|c|c|c|c|c|c|c|c|c|c|}
\hline Sample No. & $\underset{\%}{\mathrm{Agg}}$ & $\begin{array}{c}\text { Asphalt } \\
\%\end{array}$ & & eight ( $g_{1}$ & & (b)-(a) & $\begin{array}{c}\text { Bulk } \\
\text { Specific } \\
\text { Gravity } \\
(\mathrm{Gmb})\end{array}$ & $\begin{array}{l}\text { Asphalt } \\
\text { Gs }\end{array}$ & $\begin{array}{l}\text { Gse } \\
\text { of } \\
\text { Agg }\end{array}$ & $\begin{array}{c}\text { Max } \\
\text { Theoretical } \\
\text { Gs (Gmm) }\end{array}$ & $\begin{array}{l}\% \text { Air } \\
\text { Voids }\end{array}$ & $\begin{array}{c}\text { Voids in } \\
\text { Mineral } \\
\text { Aggregate } \\
\text { (VMA) } \\
\%\end{array}$ & $\begin{array}{c}\text { Voids } \\
\text { Filled } \\
\text { with } \\
\text { Asphalt } \\
\text { (VFA) } \\
\%\end{array}$ \\
\hline \multicolumn{14}{|c|}{ Before recycling wearing course cores } \\
\hline BRR-1-8 & 95.1 & 4.9 & 789.8 & 469.2 & 790.8 & 321.6 & 2.46 & 1.03 & 2.76 & 2.55 & 3.70 & 14.2 & 73.9 \\
\hline BRL-2-4 & 94.9 & 5.1 & 867.4 & 515.5 & 868.4 & 352.9 & 2.46 & 1.03 & 2.76 & 2.54 & 3.32 & 14.3 & 76.8 \\
\hline $\mathrm{BRC}-3-6$ & 94.8 & 5.2 & 836.5 & 495.9 & 833.3 & 337.4 & 2.44 & 1.03 & 2.76 & 2.54 & 2.33 & 13.6 & 82.9 \\
\hline Average & 95 & 5.0 & & & & & 2.46 & & & & 3.12 & 14.0 & 77.9 \\
\hline \multicolumn{14}{|c|}{ After recycling wearing course cores } \\
\hline ARL1-8 & 94.5 & 5.5 & 830 & 472.8 & 830 & 357.4 & 2.34 & 1.03 & 2.70 & 2.48 & 6.32 & 17.6 & 64.1 \\
\hline ARL2-9 & 94.4 & 5.6 & 852.4 & 477.8 & 856 & 378.2 & 2.28 & 1.03 & 2.70 & 2.48 & 8.95 & 20.1 & 55.5 \\
\hline ARL3-3 & 94.2 & 5.8 & 694.8 & 385.8 & 693 & 307.2 & 2.26 & 1.03 & 2.70 & 2.47 & 8.36 & 20.0 & 58.2 \\
\hline Average & 94.4 & 5.6 & & & & & 2.30 & & & & 7.8 & 19.2 & 59.3 \\
\hline
\end{tabular}

Note: Agg stands for Aggregate 


\section{Reclaimed asphalt binder testing}

The penetration grade as well as the performance grade (PG) of recovered asphalt binder from asphalt cores before recycling was determined. Penetration grade was determined according to ASTM D 5-06 e1. Penetration grades of recovered asphalt binder before recycling ranged between 55 and 57 whereas after recycling they ranged between 58 and 60.

The PG (higher temperature only) was determined by Dynamic Shear Rheometer (DSR) according to AASHTO T 315-06. The RAP binder was tested in the DSR at a high temperature as if it was original, unaged binder (McDaniel and Anderson, 2001). Performance grades of recovered asphalt binder before recycling ranged between 58 and 64 whereas after recycling ranged between 52 and 58.

\section{RESULTS AND DISCUSSION}

\section{Analysis of resilient modulus data}

Wearing course layer moduli show that the material is stiff; however, the variation of modulus was in a medium range. Average values of $17759 \mathrm{MPa}$ at $5^{\circ} \mathrm{C}, 8696 \mathrm{MPa}$ at $25^{\circ} \mathrm{C}$ and $2528 \mathrm{MPa}$ at $40^{\circ} \mathrm{C}$ (Table 5) can be taken as representative values. Test Section 1 contained a stiffer HMA layer as compared to other test sections at $25^{\circ} \mathrm{C}$ and $40^{\circ} \mathrm{C}$. Section 2 has highest modulus values at $5^{\circ} \mathrm{C}$. Overall average specific gravity of 2.44 and low VMA (14\%) shows that the material has become too dense and compacted with age which is also a cause of high modulus. This is also reflected in low air void results reported in Table 8 and wearing course high modulus values measured by Falling Weight Deflectometer (FWD) of the same sections given by Qureshi et al. (2010) for the same sections.

The results for wearing course layer moduli show that the material is of medium stiffness after hot in-place recycling. Average values of $9763 \mathrm{MPa}$ at $5^{\circ} \mathrm{C}, 3072 \mathrm{MPa}$ at $25^{\circ} \mathrm{C}$ and $757 \mathrm{MPa}$ at $40^{\circ} \mathrm{C}$ (Table 5) can be taken as representative values. Section 2 contains a stiffer HMA layer as compared to other test sections at $25^{\circ} \mathrm{C}$ whereas Section 1 contains stiffer HMA at $40^{\circ} \mathrm{C}$ and at $5^{\circ} \mathrm{C}$. Average specific gravity of 2.30 shows that density of the HMA wearing course layer has significantly reduced. This will cause the pavement to become more susceptible to rutting and moisture related damage but better resistant to fatigue cracking. Based on the above results, analysis can be summarized as follows:

- The average reduction in modulus of test sections is $45 \%, 65 \%$ and $70 \%$ at $5^{\circ} \mathrm{C}, 25^{\circ} \mathrm{C}$ and $40^{\circ} \mathrm{C}$ respectively. This reduction is probably due to the fact that HMA pavement was stiff before recycling, softened after recycling and low laydown temperatures during recycling. The average reductions in wearing course modulus, measured by FWD, of test Sections 1, 2 and 3 were $25 \%, 30 \%$ and $38 \%$ respectively, at a normalized temperature of $23^{\circ} \mathrm{C}$. (Qureshi et al., 2010).

- The reduction in stiffness of the HMA layer is probably due to addition of fresh asphalt and reduced density. 
- The significant reduction of modulus at $40^{\circ} \mathrm{C}$ will increase the pavement susceptibility to rutting and moisture related damage of HMA wearing course.

\section{Analysis of volumetrics and gradation}

The recovered asphalt binder, air voids and bulk specific gravity before recycling ranged between 4.9 and $5.2 \%, 2.33$ and $3.70 \%, 2.44$ and 2.46 (Table 6), respectively. Average air voids of $3.12 \%$ along with average bulk specific gravity of 2.46 before recycling shows that the HMA wearing course layer has become denser with age. The HMA wearing course layer important volumetric parameters were measured to be average asphalt content (5\%), average VMA (14\%) and average VFA (77.9\%), all within reasonable limits.

The recovered asphalt binder, air voids and bulk specific gravity after recycling range between 5.5 and $5.8 \%, 6.32$ and $8.95 \%, 2.26$ and 2.34 (Table 6), respectively. Average air voids of $7.8 \%$ along with average specific gravity of 2.30 after recycling shows an increase in air voids and reduction in density as compared to volumetric data before recycling. Insufficient compaction seems to be one of the causes of the reduction in density, even after fresh asphalt was added to the pavement. HMA wearing course layer important volumetric parameters show a trend of increase in asphalt content $(5.5 \%)$ and VMA $(19.2 \%)$ and decrease in VFA (59.3\%) but all within reasonable limits. It is assumed that reduction in stiffness in the HMA wearing course layer is due to a combination of higher asphalt content, finer gradation, lower density and increased VMA. This follows the finding of a study carried out by Roque et al. (2002) that mixes with higher VMA exhibited lower stiffness.

The gradation envelopes of HMA wearing course before and after recycling are illustrated in Figure 8 and 9. The gradation of HMA wearing course before recycling (Figure 8) was well within the gradation envelope of NHA "Class B" specification. The degradation of the aggregates in HMA wearing course due to scarification (after recycling) was observed as illustrated in Figure 9. However it remained within the limits of NHA "Class B" asphalt wearing course specifications.

Based on personal observation of the writer, visible fractured aggregate in Figure 6, low laydown temperatures of recycled HMA, relatively low densities achieved in the field, it seems that heat could not penetrate the whole $5 \mathrm{~cm}$ depth of wearing course. The fast speed of the HIR train to achieve a target of $1 \mathrm{~km}$ in 9 hours seems to be one of the causes of insufficient heat penetration in the wearing course. Compaction was done with normal procedure of break down rolling by vibratory roller, intermediate rolling by Pneumatic-tired roller (PTR) and then finish rolling by vibratory roller (without vibration).

\section{Analysis of reclaimed asphalt data}

Based on the results, analysis can be summarized as follows:

- Binder has softened, but not significantly, after recycling as indicted by penetration results given in Section: "Reclaimed asphalt binder testing" above. The softening of asphalt binder is probably due to addition of fresh asphalt and low temperatures during the recycling process. Increase in penetration showed that the effect of infra-red heating was relatively gentle and its effects on age 
hardening were negligible. Based on the limited number of samples used for extracting binder, it is recommended to further investigate the effects HIR has on binder properties.

- There is no significant change in PG after recycling given in Section: "Reclaimed asphalt binder testing" above. This further highlights the need for further investigation of studying the effects of HIR on binder.

\section{CONCLUSIONS}

Based on the results of the field, laboratory investigations and data analysis conducted during the investigation of hot in-place recycling effects on HMA wearing course on Lahore-Islamabad Motorway, the following conclusions are inferred

The M-2 test sections contained stiff and aged HMA layer with presence of medium level rutting. The penetration and performance grade of binder showed that effect of infra-red heating was gentle and binder has softened minutely, probably due to addition of fresh asphalt. Recycled wearing course seems to be structurally sound on the basis of resilient modulus test results whose values were in medium range. Insufficient heat penetration was inferred in the wearing course due to fast speed of HIR train. In-place air voids of recycled wearing course are lower probably due to lower mix temperature and insufficient compaction.

\section{RECOMMENDTIONS}

In order to expand and further validate this research, a proper mix design procedure for hot in-place recycling (HIR) should be developed and validated by project specific studies and refined through experience in Pakistan. This HIR mix design procedure should ensure the proper design requirements of asphalt and aggregate. Proper mixing and laydown temperature, of pavements to be recycled, should be maintained at site to ensure long service life and better performance. Rheological properties of binder after HIR should be further studied with consideration for the local climate in Pakistan. A detailed study should be made on effect of different rejuvenators on performance of Binder in local environments to maximize the gain from HIR wearing course.

\section{REFERENCES}

AASHTO (1993). "Guide for design of pavement structures". American Association of State Highway and Transportation Officials, Washington, DC, USA.

Barksdale, R. D., Alba, J., Khosla, N. P., Kim, R., P. C. Lambe, P. C., and Rehman, M. S. (1997). "Laboratory Determination of Resilient Modulus for Flexible Pavement Design." NCHRP Web Document 14 (Project 1-28): Contractor's Final Report, TRB, National Research Council, Washington, D.C., USA.

Kandhal, P. S., and Mallick, R. B. (1997). "Pavement Recycling Guidelines for State and Local Governments - Participant's Reference Book". Publication FHWA-SA-98042. National Center for Asphalt Technology, Auburn, AL, USA. 
McDaniel, R. and Anderson, R. M. (2001). "Recommended Use of Reclaimed Asphalt Pavement in the Superpave Mix Design Method: Technician's Manual". NCHRP Report 452, TRB, National Research Council, Washington, D.C., USA.

Qureshi, N. A., Akram, T., and Ali, S. (2010). Field Evaluation of Hot In-Place Recycling Experience in Pakistan - A Case Study. Proceedings of the $1^{\text {st }}$ Makassar Conference in Civil Engineering, Makassar, South Sulawesi, Indonesia.

Roberts, F. L., Kandhal, P.S., Brown, E.R., Lee, D.Y., and Kennedy, T.W. (2009). "Hot Mix Asphalt Materials, Mixture, Design and Construction". National Asphalt Pavement Association Research and Educational Foundation, Lanham, Maryland, USA.

Roque, R., Birgission, B., Tia, M., and Nukunya, B. (2002). "Evaluation of Superpave Criteria for VMA and Fine Aggregate Angularity: Voids in Mineral Aggregate (VMA)". Florida Department of Transportation Report No. WP10510865, Vol. 1 of 2.

Von Quintus, H.L. and Simpson, A.L. (2002). "Backcalculation of Layer Parameters for LTPP Test Sections" Layered Elastic Analysis for Flexible and Rigid Pavements, Research Report, Volume II, Long-Term Pavement Performance Program, Federal Highway Administration, Washington, DC, USA. 